\title{
Preparation and Evaluation of Phospholipid-Based Complex of Standardized Centella Extract (SCE) for the Enhanced Delivery of Phytoconstituents
}

\author{
Suprit D. Saoji, ${ }^{1}$ Nishikant A. Raut, ${ }^{1}$ Pradip W. Dhore, ${ }^{1}$ Chandrashekhar D. Borkar, ${ }^{1}$ \\ Michael Popielarczyk, ${ }^{2}$ and Vivek S. Dave ${ }^{2,3}$
}

Received 4 August 2015; accepted 17 October 2015; published online 12 November 2015

\begin{abstract}
In the present study, a phospholipid-based complex of standardized Centella extract (SCE) was developed with a goal of improving the bioavailability of its phytoconstituents. The SCE-phospholipid complex was prepared by solvent evaporation method and characterized for its physicochemical and functional properties. Fourier transform infrared spectroscopy (FTIR), differential scanning calorimetry (DSC), scanning electron microscopy (SEM), photomicroscopy, and powder x-ray diffraction (PXRD) were used to confirm the formation of Centella naturosome $(\mathrm{CN})$. The prepared complex was functionally evaluated by apparent solubility, in vitro drug release, ex vivo permeation, and in vivo efficacy studies. The prepared CN exhibited a significantly higher (12-fold) aqueous solubility $(98.0 \pm 1.4 \mu \mathrm{g} / \mathrm{mL}$ ), compared to the pure SCE $(8.12 \pm 0.44 \mu \mathrm{g} / \mathrm{mL})$, or the physical mixture of SCE and the phospholipid $(13.6 \pm 0.4 \mu \mathrm{g} / \mathrm{mL})$. The in vitro dissolution studies revealed a significantly higher efficiency of $\mathrm{CN}$ in releasing the SCE $(99.2 \pm 4.7, \% w / w)$ in comparison to the pure SCE $(39.2 \pm 2.3, \% w / w)$, or the physical mixture $(42.8 \pm 2.09, \% w / w)$. The ex vivo permeation studies with the everted intestine method showed that the prepared CN significantly improved the permeation of SCE $(82.8 \pm 3.7, \% w / w)$, compared to the pure SCE $(26.8 \pm 2.4, \% w / w)$, or the physical mixture $(33.0 \pm 2.7, \% w / w)$. The in vivo efficacy studies using the Morris Water Maze test indicated a significant improvement of the spatial learning and memory in aged mice treated with $\mathrm{CN}$. Thus, drug-phospholipid complexation appears to be a promising strategy to improve the aqueous solubility and bioavailability of bioactive phytoconstituents.
\end{abstract}

KEY WORDS: drug-phospholipid complex; permeability; phytoconstituents; solubility.

\section{INTRODUCTION}

The use of natural products in the management of several diseases/disorders have gained popularity in recent years. However, their use as pharmaceutical drug products is limited due to the poor oral bioavailability of bioactive phytoconstituents. The poor bioavailability of these pharmacologically active components is mainly attributed to the high molecular weight/size, poor aqueous/lipid solubility, and lower plasma membrane permeability, thereby limiting their use for the effective treatment of various diseases and disorders $(1,2)$.

$\overline{\text { Suprit D. Saoji and Nishikant A. Raut contributed equally to this }}$ work.

Electronic supplementary material The online version of this article (doi:10.1208/s12248-015-9837-2) contains supplementary material, which is available to authorized users.

${ }^{1}$ Department of Pharmaceutical Sciences, Rashtrasant Tukadoji Maharaj Nagpur University, Nagpur, India.

${ }^{2}$ Wegmans School of Pharmacy, St. John Fisher College, Rochester, New York 14534, USA.

${ }^{3}$ To whom correspondence should be addressed. (e-mail: viveksdave@gmail.com)
Improving the bioavailability of these bioactive compounds via improving the solubility and the permeability remains a major bottleneck in the development of pharmaceutical drug products from these entities. Among the several approaches explored in recent years for the improvement of bioavailability of drugs, drug-phospholipid complexes appear to be among the promising ones. Incorporating bioactive phytoconstituents into phospholipid molecules is reported to improve the aqueous solubility, the membrane permeability, and hence the systemic absorption and bioavailability of the active phytoconstituents. Such complexes are appropriately called phytosomes, herbosomes, or naturosomes $(3,4)$. Studies have reported success in improving the pharmacological profiles of several bioactive phytoconstituents using drugphospholipid complexation technique (5-9).

Alzheimer's disease (AD) is an irreversible, neurodegenerative disorder resulting in a progressive decline of cognitive and functional abilities, with impairment of memory and thinking skills (10). Alzheimer's association projects the incidence of AD to 1 million people annually and estimates the total prevalence of the disorder to 11-16 million people, by the year 2050 (11). Current AD interventions include symptomatic treatment with cholinesterase inhibitors (ChEIs) such as donepezil, and N-methyl-D-aspartase receptor 
antagonists such as memantine (12). However, the progression of the disease, and the associated neuronal degeneration continues, in addition to the adverse effects of this treatment (13). In 2004, the US FDA-approved galantamine, a phytoconstituent obtained from Galanthus nivalis, for the treatment of $\mathrm{AD}$ with the reported mechanism being the inhibition of acetyl cholinesterase (14). Recently, some herbal extracts such as those of Ginkgo biloba, and other phytochemicals such as evodiamine have also been explored for their anti-AD properties in animals and humans (15-19).

Centella asiatica Linn. (Apiaceae), a perennial creeper found throughout most tropical and subtropical countries, is reported to be useful for anxiety, memory enhancement, and neuroprotection (20). The major chemical constituents reported to be responsible for its pharmacological activity are triterpenes based on steroidal moieties, such as asiaticoside, asiatic acid, madecassoside, and madecassic acid (21). Several pharmaceutical products containing $C$. asiatica are commercially available and are recommended for enhancing memory in patients with memory deficit (22). The usefulness of any pharmaceutical product depends on the safety, efficacy, and the quality of that product. A quality by design (QbD) approach is now considered to be an ideal pathway to ensure the development of a quality product, and the minimization of product variabilities. QbD is broadly defined as a scientific, risk-based, holistic, and a proactive approach to pharmaceutical development that begins with predefined objectives, and emphasizes the understanding and control of the product and processes based on sound science, and quality risk management (23). Despite the commercial availability of several pharmaceutical products containing extracts of $C$. asiatica, the issue of the low aqueous solubility of the extract remains practically unaddressed.

Thus, the primary goal of the current study was to evaluate the feasibility of enhancing the aqueous solubility of standardized Centella extract (SCE) by preparing its vesicular complex with hydrogenated soy phosphatidylcholine (Phospholipon ${ }^{\circledR}$ 90H). This complex is hereby referred to as Centella naturosome $(\mathrm{CN})$. To address this objective, $\mathrm{CN}$ was prepared using a solvent evaporation method. The formulation and the process variables for the preparation of the $\mathrm{CN}$ were optimized using a $\mathrm{QbD}$ approach. Response surface analysis by the means of central composite design was employed for the optimization of the critical process parameters (CPP) on the SCE entrapment rate of CN. The prepared $\mathrm{CN}$ were evaluated for their physicochemical, functional, and preliminary pharmacological properties.

\section{MATERIALS AND METHODS}

\section{Materials}

The standardized Centella extract (SCE), containing $\sim 30 \%$ triterpenes was obtained from Natural Remedies Ltd., Bangalore, India. The identity of the SCE was confirmed by high performance-liquid chromatography (HPLC) analysis. Hydrogenated soy phosphatidylcholine (Phospholipon $\AA$ 90H) was generously gifted by Lipoid, Ludwigshafen, Germany. All other chemicals and reagents used were of analytical grade.

\section{Analysis of the Triterpenes Present in SCE}

The concentrations of the triterpenes present in SCE, i.e., asiaticoside, asiatic acid, madecassoside, and madecassic acid, were determined using a modified, reverse-phase (RP)HPLC method previously described by Hashim et al. (21). Briefly, the HPLC system (Model: Prominence, Shimadzu Corporation, Kyoto, Japan) with LC solution software, equipped with a LC-20AD HPLC pump, a manual rheodyne sample injector, and an SPD-M20A detector were used. The mobile phase was composed of acetonitrile and water (25:75, $v / v)$, at a flow rate of $1.5 \mathrm{~mL} / \mathrm{min}$. A Micra- NPS RP18 column $(33 \times 8.0 \times 4.6 \mathrm{~mm}, 1.5 \mu \mathrm{m})$ was used as a stationary phase and the detector wavelength was $210 \mathrm{~nm}$ at room temperature. Throughout the study, the suitability of the chromatographic system was monitored by calculating the trailing/asymmetry factor, theoretical plates and the relative standard deviation (RSD). The calibration curves for individual triterpenes were constructed by analyzing eight concentrations of the standard solution for each triterpene and plotting peak areas versus concentration. The method was validated by analyzing the different validation characteristics such as linearity, accuracy, and precision.

\section{Preparation of $\mathbf{C N}$}

The CN were prepared by slightly modifying the solvent evaporation method described by Bhattacharyya et al. (24). Briefly, different ratios, i.e., 0.5:1, 1.01:1, 1.75:1, 2.49:1, or 3:1, of Phospholipon ${ }^{\circledR} 90 \mathrm{H}$ and SCE were placed in a $100 \mathrm{~mL}$ round bottom flask, and $40 \mathrm{~mL}$ of ethanol was added to the mixture. The reaction was controlled and maintained at various temperatures, i.e., $40^{\circ} \mathrm{C}, 44^{\circ} \mathrm{C}, 50^{\circ} \mathrm{C}, 56^{\circ} \mathrm{C}$, or $60^{\circ} \mathrm{C}$ using a water bath. The reaction was carried out for different durations, i.e., $1,1.4,2,2.6$, or $3 \mathrm{~h}$. The resulting clear solution was evaporated to $2-3 \mathrm{~mL}$, and an excess of $\mathrm{n}$-hexane was added to it with continuous stirring. The dispersion formed was then precipitated, filtered, and dried under vacuum to remove any traces of solvents. The resulting $\mathrm{CN}$ were stored at room temperature, in amber colored glass vials, flushed with nitrogen, for further testing.

\section{QbD-Based Design of Experiments}

A QbD-based approach using a central composite design to obtain a response surface design was employed to systematically study the combined influence of the formulation and process variables such as the phospholipid-to-drug ratio $\left(X_{1}, w / w\right)$, the reaction temperature $\left(X_{2},{ }^{\circ} \mathrm{C}\right)$, and the reaction time $\left(X_{3}, \mathrm{~h}\right)$ on the critical quality attributes (CQAs) of the product i.e., the entrapment efficiency. Using this design, the influence of three factors was evaluated, and the experimental trials were carried out at all 20 possible combinations $(25,26)$. A statistical model incorporating interactive and polynomial terms was used to evaluate the response employing the following Eq. (1):

$$
\begin{aligned}
Y= & b_{0}+b_{1} X_{1}+b_{2} X_{2}+b_{3} X_{3}+b_{11} X_{1}^{2}+b_{22} X_{2}^{2}+b_{33} X_{3}^{2} \\
& +b_{12} X_{1} X_{2}+b_{23} X_{2} X_{3}+b_{13} X_{1} X_{3}
\end{aligned}
$$


where $Y$ is the dependent variable, $b_{0}$ is the arithmetic mean response of the 20 runs, and $b_{i}$ is the estimated coefficient for the factor $X_{i}$. The main effects $\left(X_{1}, X_{2}\right.$, and $\left.X_{3}\right)$ represented the average result of changing one factor at a time from its low to high value. The interaction terms $\left(X_{1} X_{2}, X_{2} X_{3}, X_{1} X_{3}\right)$ showed how the response changes when all three factors were simultaneously changed. The polynomial terms $\left(X_{1}^{2}, X_{2}^{2}\right.$, and $X_{3}^{2}$ ) were included to investigate on linearity. The level values of the three factors, the real values of the central composite design batches, and the resulting entrapment efficiencies are shown in Tables I and II.

\section{Entrapment Efficiency of CN}

The entrapment efficiency, i.e., the SCE (total triterpenes content) entrapped in the naturosome was determined using a combination of methods described in the literature $(27,28)$. Briefly, accurately weighed $(100 \mathrm{mg}) \mathrm{CN}$ powder was dispersed in $10 \mathrm{~mL}$ chloroform. The $\mathrm{CN}$ and Phospholipon ${ }^{\circledR}$ $90 \mathrm{H}$ both were easily dissolved in the chloroform. The SCE was not entrapped in the $\mathrm{CN}$ was collected as a sediment and assayed by HPLC. The entrapment efficiency of the prepared $\mathrm{CN}$ was calculated using the following Eq. (2):

Entrapment efficiency $(\%)=\frac{C_{t}-C_{f}}{C_{t}} \times 100$

where $C_{t}$ is the total concentration of SCE, and $C_{f}$ is the SCE contained in the filtrate.

\section{Determination of SCE Content in $\mathrm{CN}$}

The SCE content in the CN was determined by HPLC method described above. The drug content was calculated using Eq. (3) below, previously described by Bhattacharya et al. (29).

Drug content $(\%)=\frac{\text { Amount of drug in } \mathrm{CN}}{\text { Amount of } \mathrm{CN}} \times 100$

\section{Physico-Chemical Characterization of CN}

\section{Photomicroscopy}

For the microscopic characterization of the prepared naturosomes, a suspension containing approximately $100 \mathrm{mg}$

Table I. Coded Levels and "Real" Values for each Factor under Study

\begin{tabular}{llllll}
\hline \multicolumn{7}{l}{ Levels } & & & \\
\cline { 2 - 6 } Variables & -1.7 & -1 & 0 & +1 & +1.7 \\
\hline Independent & Real values & & & \\
Phospholipid/drug ratio $\left(X_{1}, w / w\right)$ & 0.5 & 1.0 & 1.8 & 2.5 & 3.0 \\
Reaction temperature $\left(X_{2},{ }^{\circ} \mathrm{C}\right)$ & 40.0 & 44.0 & 50.0 & 56.0 & 60.0 \\
Reaction time $\left(X_{3}, \mathrm{~h}\right)$ & 1.0 & 1.4 & 2.0 & 2.6 & 3.0 \\
Dependent & & & & & \\
Entrapment efficiency $(Y, \% w / w)$ & & & & & \\
\hline
\end{tabular}

Table II. Central Composite Design Formulation Batches with Respective Entrapment Efficiencies

\begin{tabular}{lllll}
\hline Batches & $X_{1}$ & $X_{2}$ & $X_{3}$ & Entrapment efficiency* $(\%, w / w)$ \\
\hline F1 & -1 & +1 & +1 & $83.2 \pm 1.3$ \\
F2 & -1 & -1 & +1 & $89.2 \pm 0.8$ \\
F3 & +1.7 & 0 & 0 & $95.1 \pm 1.1$ \\
F4 & +1 & -1 & +1 & $86.4 \pm 1.3$ \\
F5 & 0 & 0 & -1.7 & $76.7 \pm 0.9$ \\
F6 & -1.7 & 0 & 0 & $58.1 \pm 1.1$ \\
F7 & 0 & 0 & +1.7 & $94.4 \pm 1.2$ \\
F8 & +1 & +1 & +1 & $94.3 \pm 1.0$ \\
F9 & 0 & -1.7 & 0 & $79.4 \pm 0.9$ \\
F10 & -1 & -1 & -1 & $64.7 \pm 0.9$ \\
F11 & -1 & +1 & -1 & $71.5 \pm 0.8$ \\
F12 & 0 & +1.7 & 0 & $90.9 \pm 1.3$ \\
F13 & +1 & +1 & -1 & $90.0 \pm 1.1$ \\
F14 & +1 & -1 & -1 & $82.2 \pm 1.6$ \\
F15-F20 & 0 & 0 & 0 & $91.4 \pm 0.9$ \\
\hline
\end{tabular}

*Values represent mean \pm standard deviation $(n=3)$

of the naturosome powder was transferred to a glass tube and diluted with 10-mL phosphate buffer saline (PBS, pH 7.4). The suspended vesicles were then mounted on a clear glass slide and photomicrographs were captured with a microscope (Model: DM 2500, Leica Microsystems, Germany) under $\times 20$ magnification.

\section{Scanning Electron Microscopy}

The $\mathrm{CN}$ powder obtained from the optimized formulation batches was sprinkled on a double-sided carbon tape, and the tape was placed on a brass stub. The surface powder was coated with a thin layer of palladium using the auto fine coater (Model: JFC1600, Jeol Ltd., Tokya, Japan). The palladium coated samples were observed using a scanning electron microscope (Model: JSM-6390LV, Jeol Ltd, Tokyo, Japan) equipped with a digital camera, at $10-\mathrm{KV}$ accelerating voltage.

\section{Particle Size and Zeta Potential Analysis}

The particle size analysis of the prepared $\mathrm{CN}$ was carried out using photon correlation spectroscopy (PCS), with dynamic light scattering on a Zetasizer ${ }^{\circledR}$ nano (Model: Zen 3600, Malvern Instruments, Malvern, UK) equipped with a $5 \mathrm{~mW}$ He-Ne laser with a wavelength output of $633 \mathrm{~nm}$. The measurements were carried out at $25^{\circ} \mathrm{C}$, at an angle of $90^{\circ}$ and a run time of at least $40-80 \mathrm{~s}$. Water was used as a dispersant. The zeta potential was measured by Smoluchowski's equation from the electrophoretic mobility of naturosomes (30). All measurements were performed in triplicate.

\section{Fourier Transform Infrared Spectroscopy}

The infrared spectra of neat SCE, Phospholipon ${ }^{\circledR} 90 \mathrm{H}$, the physical mixture of SCE with Phospholipon ${ }^{\circledR} 90 \mathrm{H}$ (PM), and the prepared $\mathrm{CN}$ were obtained from an FTIR spectrophotometer (Model: IR Prestige-21, Shimadzu, Japan) equipped with an attenuated total reflectance (ATR) 
accessory. The analysis of the samples was carried out using diffuse reflectance spectroscopy using $\mathrm{KBr}$ compacts. The influence of the residual moisture was theoretically removed by subjecting the samples to vacuum drying before obtaining any spectra. Each sample analysis included 45 scans, at a resolution of $4 \mathrm{~cm}^{-1}$ in the wavelength range 4000 to $600 \mathrm{~cm}^{-1}$.

\section{Differential Scanning Calorimetry}

The thermal analysis of the samples (SCE, Phospholipon ${ }^{\circledR} 90 \mathrm{H}, \mathrm{PM}$, and $\mathrm{CN}$ ) was carried out using a differential scanning calorimeter (Model: Q20, TA Instruments, Inc., New Castle, DE, USA). The analysis was performed under a purge of dry nitrogen gas $(50 \mathrm{~mL} / \mathrm{min})$. High-purity indium was used to calibrate the heat flow and the heat capacity of the instrument. The samples $(\sim 5 \mathrm{mg})$ were held in open-standard aluminum pans. Each sample was subjected to a single heating cycle from $0^{\circ} \mathrm{C}$ to $400^{\circ} \mathrm{C}$ at a heating rate of $10^{\circ} \mathrm{C} / \mathrm{min}$. The peak transition onset temperatures of samples were analyzed using the Universal Analysis software version 4.5A, build 4.5.0.5 (TA Instruments, Inc., New Castle, DE, USA) (31).

\section{Powder X-Ray Diffraction}

The polymorphic state of the samples (SCE, Phospholipon $\AA 90 \mathrm{H}, \mathrm{PM}$, and $\mathrm{CN}$ ) was evaluated using a powder x-ray diffractometer (Model: D2 Phaser, Bruker AXS, Inc., Madison, WI, USA), equipped with a BraggBrentano geometry $(\theta / 2 \theta)$ optical setup. The samples were scanned with the diffraction angle increasing from $2^{\circ}$ to $90^{\circ}$, $2 \theta$ angle, with a step-angle of $0.2^{\circ} 2 \theta$ and a count time of $0.5 \mathrm{~s}$.

\section{Functional Evaluation of $\mathbf{C N}$}

\section{Apparent Solubility Analysis}

The apparent solubility of the samples was determined by a method previously described by Singh et al. (32). Briefly, an excess of SCE and $\mathrm{CN}$ were added to $10 \mathrm{~mL}$ of water or $\mathrm{n}$ Octanol in sealed glass containers at room temperature $\left(25^{\circ} \mathrm{C}\right)$. The liquid was agitated for $24 \mathrm{~h}$, followed by centrifugation for $30 \mathrm{~min}$ at $4000 \mathrm{RPM}$. The supernatant was filtered through a membrane filter $(0.45 \mu)$. One milliliter of this filtrate was mixed with mobile phase to prepare appropriate dilutions, and the samples were analyzed at $210 \mathrm{~nm}$ using the RP-HPLC method described earlier.

\section{In Vitro Drug Release (Dissolution)}

The in vitro dissolution study was carried out using the method described previously by Zhang et al. (33). Accurately weighed samples equivalent to $50 \mathrm{mg}$ of SCE were added to the surface of the stirred dissolution medium $(900 \mathrm{~mL}$ phosphate buffer, $\mathrm{pH}$ 6.8) at the beginning of the study in a USP type II dissolution apparatus (Model: TDT-06T, Electrolab India Pvt. Ltd., India). The dissolution was carried out at $100 \mathrm{rpm}$ and $37^{\circ} \mathrm{C}$. Samples $(10 \mathrm{~mL})$ from the dissolution medium were withdrawn at regular time intervals and replaced with an equal volume of fresh medium to maintain sink conditions. The samples were filtered through a membrane filter $(0.45 \mu)$, diluted suitably with mobile phase to prepare dilutions, and analyzed using the RP-HPLC method described earlier.

\section{Dissolution Efficiency}

The dissolution efficiency (DE) of the SCE, PM, and CN in the phosphate buffer saline was evaluated at $12 \mathrm{~h}$. The dissolution efficiency was calculated using Eq. (4), previously described by Anderson et al. (34).

$\mathrm{DE}=\frac{\int_{t_{1}}^{t_{2}} y \cdot d t}{y_{100} \times\left(t_{2}-t_{1}\right)} \times 100$

where $y$ is the percentage of dissolved drug. DE is the area under the dissolution curve between time points $t_{1}$ and $t_{2}$ expressed as a percentage of the curve at maximum dissolution, $y_{100}$, over the same time period. The integral of the numerator, i.e., the area under the curve was calculated by a model independent trapezoidal method as defined by the Eq. (5).

$\mathrm{AUC}=\sum_{i=1}^{i=n} \frac{\left(t_{1}-t_{i-1}\right)\left(y_{i-1}+y_{i}\right)}{2}$

Where $t_{i}$ is the $i$ th time point and $y_{i}$ is the percentage of dissolved drug at time $t_{i}$.

\section{Ex Vivo Permeability}

Perfusion Apparatus. The apparatus used in this study was previously described by Dixit et al. (35) which consisted of two glass tubes held together by a glass joint on the upper end with open tapering ends facing towards each other. A provision for mounting the tissue is facilitated in the form of a bulge at the ends of both tubes. The dimensions of the apparatus $(18 \mathrm{~cm} \times 4 \mathrm{~cm} \times 2 \mathrm{~cm})$ are such that it can be conveniently set up in a $250-\mathrm{mL}$ glass measuring cylinder. After mounting the everted intestinal segment on the apparatus, the whole assembly is kept in a glass measuring cylinder; the inside of the glass tubes serve as the receiver compartment and the outside serves as the donor compartment.

Isolation and Eversion of the Intestine. Ethical clearance for the handling of experimental animals was obtained from the institutional animal ethics committee (IAEC) formed for this purpose. The Sprague-Dawley ${ }^{\circledR}$ rats (200-250 g) were fasted overnight. The rat was euthanized humanely by cervical dislocation, midline incision was given to open the abdomen, and the intestine was carefully maneuvered to identify the ileocecal junction. About 7-cm long intestine (jejunum) was removed from the mesenteric attachments carefully without damaging the intestine. The isolated piece of intestine was thoroughly washed with Kreb's solution, everted using glass rod, and transferred to a petri dish 
containing Kreb's solution. A 6 cm everted segment was used for permeability experiments.

Permeability Determination. The everted piece of intestine was mounted between the two tapered ends of the perfusion apparatus. The perfusion apparatus was filled with Kreb's solution and immersed in the measuring cylinder $(250 \mathrm{~mL})$ containing SCE, PM, or CN $(100 \mu \mathrm{g} / \mathrm{mL})$ in $250 \mathrm{~mL}$ Kreb's solution. The whole assembly was placed on a constant temperature $\left(37^{\circ} \mathrm{C}\right)$ magnetic stirrer and the content stirred at 25 RPM. Additionally, the Kreb's solution was constantly aerated with carbogen (oxygen/carbon dioxide (95:5) mixture). The samples were collected at $15 \mathrm{~min}$ interval up to $3 \mathrm{~h}$ and analyzed by HPLC for estimation of permeability.

\section{Preliminary Pharmacological Evaluation (In Vivo Efficacy)}

Animals. Young (3-4 months) and aged (22-24 months), male Swiss albino mice were group housed under constant room temperature $\left(25^{\circ} \mathrm{C} \pm 2^{\circ} \mathrm{C}\right)$, relative humidity $(50 \%-70 \%$ $\mathrm{RH})$, and maintained on a 12-h:12-h light/dark cycle. Food and water were given ad libitum except for during the experiment. All procedures and protocols employed in the study were approved and carried out under strict compliance with the Institutional Animal Ethics Committee, Department of Pharmaceutical Sciences, R. T. M. Nagpur University, Nagpur, MS, India.

Morris Water Maze Test (MWM). The MWM test was performed to compare the pharmacological efficacy of the prepared $\mathrm{CN}$ with that of SCE in spatial learning and memory in mice. MWM test is among the most widely used behavioral models employed for screening of antiAlzheimer's activity in the rodents. The standard protocol previously described by Vorhees et al. was employed with some modifications (36). Briefly, the animals were acclimatized to the laboratory conditions for a week before performing the actual experiments. MWM consists of a large circular pool measuring $90 \mathrm{~cm}$ in diameter and $40 \mathrm{~cm}$ in height. The maze was filled with water $\left(25^{\circ} \mathrm{C}\right)$ to a height of $30 \mathrm{~cm}$, and rendered opaque using milk. The pool was arbitrarily divided into four compass quadrants, and a white escape platform (10 cm in diameter) was submerged in one of the quadrants, $1 \mathrm{~cm}$ below the water surface. The location of platform remained fixed for all 4 days of training sessions.

The animals were divided into seven groups with six animals in each group $(n=6)$, i.e., group $1=$ young mice (vehicle), group $2=$ aged mice (vehicle), group $3=$ Phospholipon ${ }^{\circledR} 90 \mathrm{H}(900 \mathrm{mg} / \mathrm{kg})$, group $4=$ piracetam $(200 \mathrm{mg} / \mathrm{kg})$, group $5=\operatorname{SCE}(300 \mathrm{mg} / \mathrm{kg})$, group $6=\mathrm{PM}$ (equivalent to $300 \mathrm{mg} / \mathrm{kg} \mathrm{SCE}$ ), and group $7=\mathrm{CN}$ (equivalent to $300 \mathrm{mg} / \mathrm{kg} \mathrm{SCE}$ ). The doses used in the present study were reported effective in the animals $(37,38)$. All animals received their respective treatments orally, each day, $1 \mathrm{~h}$ before the experiment. Each mouse was given four training sessions per day, at an interval of $10 \mathrm{~min}$ between the training sessions, for 4 consecutive days. The starting locations for the animals varied quasi-randomly, and the cutoff time was fixed at $120 \mathrm{~s}$. The length of time taken by the animal to locate the platform was measured as escape latency. If the animal failed to escape within $120 \mathrm{~s}$, it was manually placed on the platform for $30 \mathrm{~s}$, and the escape latency was recorded as $120 \mathrm{~s}$. A single $120 \mathrm{~s}$ probe trial was also conducted on the fifth day ( $24 \mathrm{~h}$ after the last acquisition trial), to measure the time spent in the target quadrant, as a measure of memory retention.

\section{RESULTS AND DISCUSSION}

\section{Preparation of $\mathbf{C N}$}

The initial investigation of the influence of factors revealed that all the studied factors, i.e., the phospholipidto-drug ratio, the reaction temperature, and the reaction time had a significant influence on the entrapment efficiency of the prepared naturosomes. The results of the entrapment efficiency (\%) are shown in Table II. The measured values from the experimental trials revealed a wide range (58.1-95.1, \% $w / w)$ entrapment efficiencies (Table II). The fitted polynomial equations relating the response (entrapment efficiency, \% $w / w$ ) to the transformed factors are shown in Fig. 1. The polynomial equations could be used to draw conclusions after considering the magnitude of the coefficient, and its associated mathematical sign, i.e., positive or negative. The results from Fig. 1 also indicated that all the coefficients, i.e., $b_{1}, b_{2}, b_{3}, b_{11}, b_{22}, b_{33}, b_{12}$, $b_{23}$, and $b_{13}$ were statistically significant $(p<0.05)$. The value of correlation coefficient $\left(R^{2}\right)$ was found to be 0.9369 , indicating a good fit to the quadratic model. The multiple regression analysis (Fig. 1) revealed that the coefficients $b_{1}, b_{2}$, and $b_{3}$ were positive. This indicated that the entrapment efficiency increased with increasing $X_{1}, X_{2}$, and $X_{3}$. The data further indicated that the quadratic model is statistically significant $\left(F_{\text {critical }}\right.$ value $=16.5$; $p<0.001$ ) (Suppl. Table 1).

Based on the central composite design, the response surface and contour plots depicting the changes in the entrapment efficiency (\%) as a function of $X_{1}, X_{2}$, and $X_{3}$ were created (Suppl. Fig. 1). The data from all 20 batches of the central composite design were used for generating interpolated values using Design Expert 9, version 9.0.4.1 (Stat-Ease, Inc., Minneapolis, MN). The response surface and contour plots indicated a strong influence of the studied factors $X_{1}, X_{2}$, and $X_{3}$ on the entrapment efficiency. Increasing levels of $X_{1}, X_{2}$, and $X_{3}$ were found to be favorable conditions for obtaining higher entrapment efficiency. Based on these observations, along with the multiple regression model, the optimal values of the studied factors, i.e., the phospholipid-to-drug ratio, the reaction temperature, and the reaction time were $3: 1,60^{\circ} \mathrm{C}$, and $3 \mathrm{~h}$, respectively.

\section{Validation of the Model}

In order to validate the developed model, an additional batch of $\mathrm{CN}$ was prepared. This validation batch was prepared using the optimal settings of the formulation and process variables from the model, i.e., $X_{1}, X_{2}$, and $X_{3}$ values of $3: 1,60^{\circ} \mathrm{C}$, and $3 \mathrm{~h}$, respectively. The predicted entrapment efficiency of the $\mathrm{CN}$ obtained from model, as well as the 


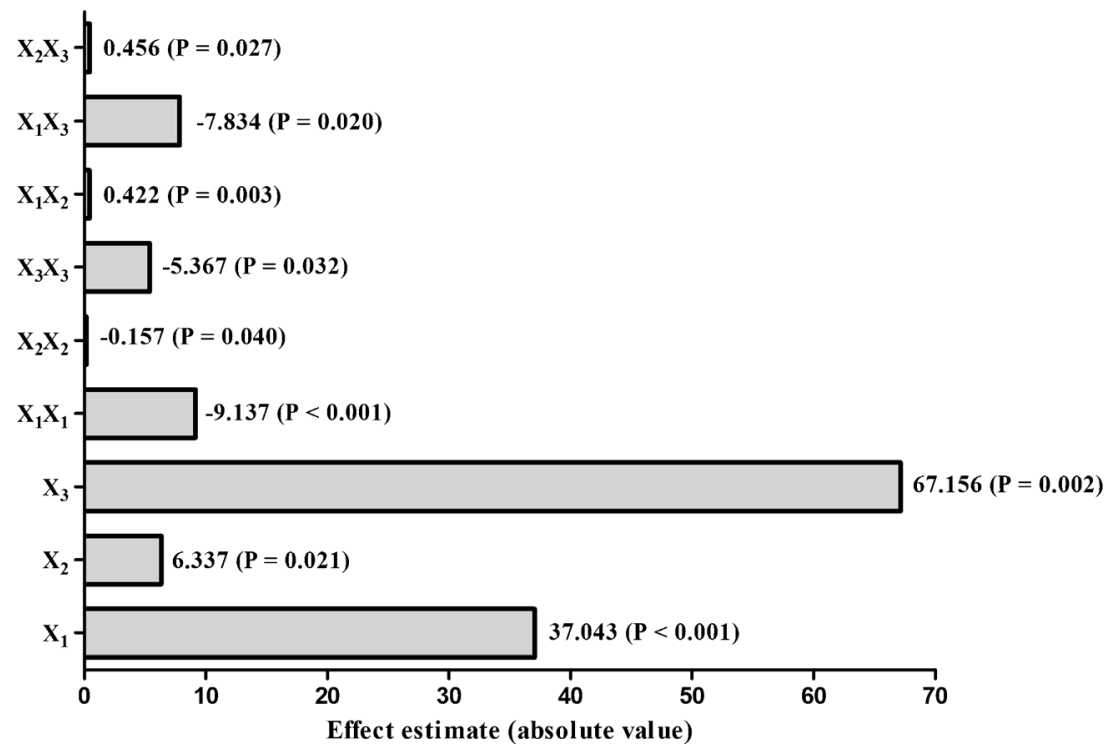

Fig. 1. Pareto diagrams for effect estimation. The effects presenting probability values higher than 0.05 are not considered as statistically significant

actual entrapment efficiency achieved from the prepared formulation were compared (Suppl. Table 2). The average entrapment efficiency of SCE in naturosomes prepared under the optimized conditions was found to be $93.9 \% \pm 1.3 \%$. These values compared well with the model-predicted value, i.e., $95.0 \%$, indicating the practicability and the validity of the developed model. The bias (\%), calculated using Eq. (6) was also found to be less than $3 \%(1.2 \%)$, indicating the relative robustness of the model (39).

$\operatorname{Bias}(\%)=\frac{\text { predicted value }- \text { observed value }}{\text { predicted value }} \times 100$

\section{Physico-Chemical Characterization of the Prepared CN}

\section{Photomicroscopy and Scanning Electron Microscopy}

The results from the initial morphological characterization of SCE and the prepared $\mathrm{CN}$ showed that the SCE appeared to be irregularly shaped, polydispersive agglomerates made up of small, crystalline particles (Suppl. Fig. 2a). Whereas, the prepared $\mathrm{CN}$ appeared to have a dramatically different morphology (Suppl. Fig. 2b). These particles were much larger entities, with a relatively rough surface; and appeared to consist of multiple layers, with possibly entrapping the SCE crystals (shown by the red pointer).

The prepared $\mathrm{CN}$ were further analyzed by scanning electron microscopy (SEM) for their surface morphology [Suppl. Fig. 3a-c]. The electron micrographs at different magnifications i.e., $\times 1000$ (Suppl. Fig. 3a), $\times 3000$ (Suppl. Fig. 3b), and $\times 6000$ (Suppl. Fig. 3c) revealed the formation of multi-layered vesicles of hydrogenated soy phosphatidylcholine. The initial morphological characterization indicated the successful formulation of phospholipid-based vesicular complex (naturosome) of SCE.

\section{Particle Size and Zeta Potential Analysis}

The mean particle size and the zeta potential values of the prepared $\mathrm{CN}$ were carried out using dynamic light scattering technique [Suppl. Fig. 4a, b]. The mean particle size of $\mathrm{CN}$ was found to be $450.1 \pm 20.0 \mathrm{~nm}$. The surface area/ volume $(\mathrm{SA} / \mathrm{V})$ ratio of most particles is inversely proportional to the particle size. Thus, smaller particles of the $\mathrm{CN}$, having a higher $\mathrm{SA} / \mathrm{V}$, makes it easier for the entrapped drug to be released from the naturosome via diffusion and surface erosion. They also have the added advantage for the drugentrapped naturosomes to penetrate into, and permeate through the physiological drug barriers. LeFevre et al. and Savic et al. have previously suggested that larger particles $(\leq 5 \mathrm{~mm})$ are taken up via the lymphatics, while the smaller particles $(\leq 500 \mathrm{~nm})$ can cross the epithelial cell membrane via endocytosis $(40,41)$. Zeta potential is another important index commonly used to assess the stability of the naturosomes. The zeta potential of the prepared $\mathrm{CN}$ was found to be $-35.0 \pm 1.9 \mathrm{mV}$. These results are in agreement with previous reports, which mentions that the zeta potential values of greater than $-30 \mathrm{mV}$ are considered acceptable, and are indicative of a good physical stability $(42,43)$.

\section{Fourier Transform Infrared Spectroscopy}

The results from the Fourier transform infrared spectroscopy (FTIR) analyses of the SCE, Phospholipon ${ }^{\circledR} 90 \mathrm{H}$, the physical mixture of SCE with Phospholipon ${ }^{\circledR} 90 \mathrm{H}(\mathrm{PM})$, and the prepared $\mathrm{CN}$ are shown in Fig. 2a-d, respectively). The FTIR spectrum of SCE (Fig. 2a) exhibited a broad peak at $3365 \mathrm{~cm}^{-1}$, representing the aliphatic alcoholic $(-\mathrm{OH})$ group substituted on the cyclic ringed structure. The $\mathrm{C}-\mathrm{H}$ stretching signal at $2926 \mathrm{~cm}^{-1}$ relates to the characteristic feature of the triterpene ring structure. The triterpene also exhibited a $\mathrm{C}=\mathrm{O}$ stretching around $1710 \mathrm{~cm}^{-1}$, along with a $\mathrm{C}=\mathrm{C}$ stretching signal at $1662 \mathrm{~cm}^{-1}$ as an associated peak possibly representing the alkene nature of neighboring ring attachments. The FTIR 

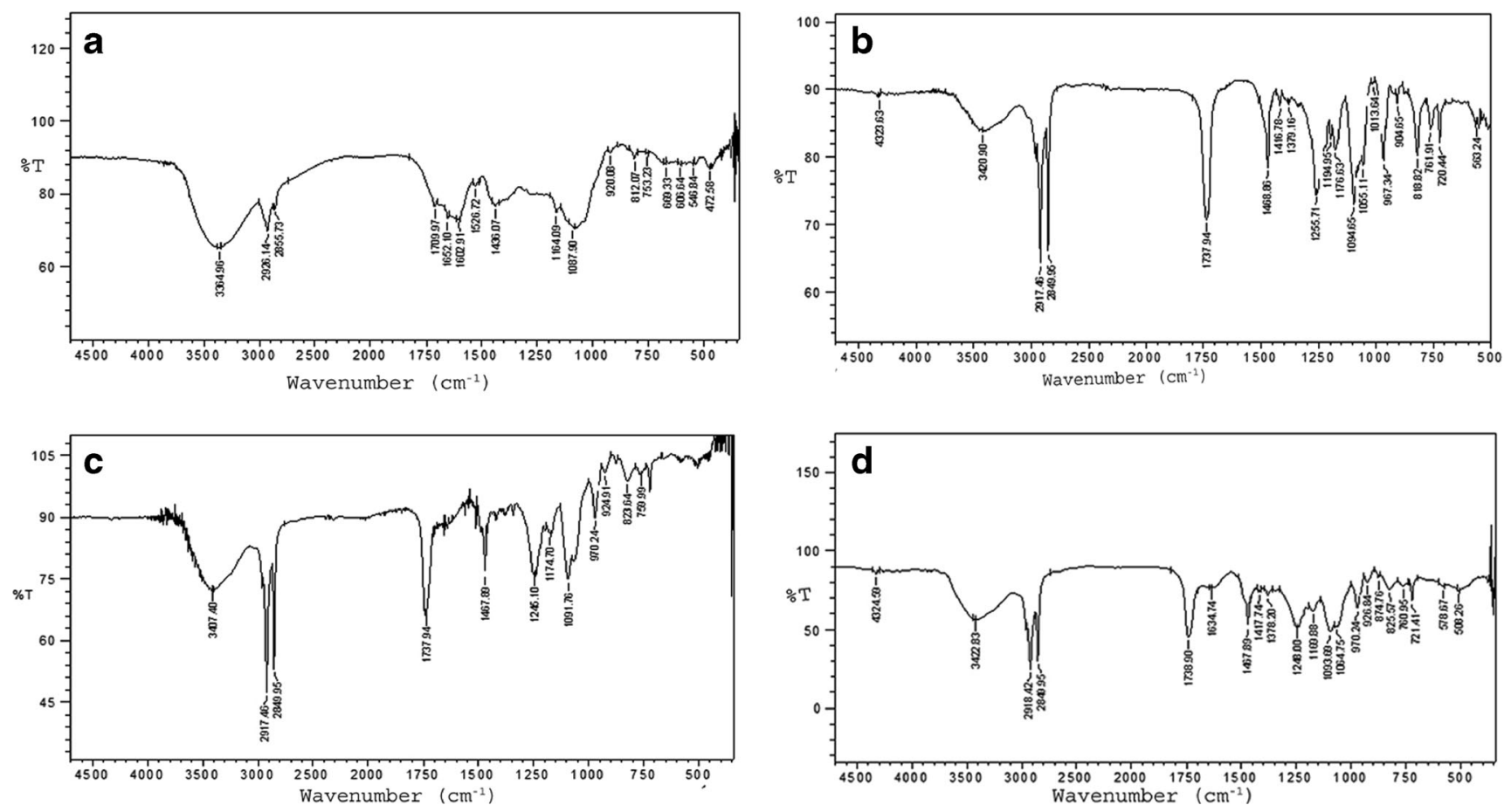

Fig. 2. FTIR spectra of a SCE, b Phospholipon ${ }^{\circledR} 90 \mathrm{H}$, c physical mixture, and d CN

spectrum of the SCE further exhibited the aromatic nature of the basic ring nucleus, with aromatic stretching signals in the region of 1602 and $1563 \mathrm{~cm}^{-1}$. Prominent peaks observed at 1164 and $1088 \mathrm{~cm}^{-1}$ typically relates to the presence of acidic functional groups $(-\mathrm{COOH})$ on the molecule.

The FTIR spectrum of Phospholipon ${ }^{\circledR} 90 \mathrm{H}$ (Fig. 2b) revealed the characteristic $\mathrm{C}-\mathrm{H}$ stretching signal present in the long fatty acid chain at 2918 and $2850 \mathrm{~cm}^{-1}$, respectively. In addition, a $\mathrm{C}=\mathrm{O}$ stretching band at $1738 \mathrm{~cm}^{-1}$ in the fatty acid ester, a $\mathrm{P}=\mathrm{O}$ stretching band at $1236 \mathrm{~cm}^{-1}$, a $\mathrm{P}-\mathrm{O}-\mathrm{C}$ stretching band at $1091 \mathrm{~cm}^{-1}$, and a $-\mathrm{N}^{+}\left(\mathrm{CH}_{3}\right)^{3}$ stretching at $970 \mathrm{~cm}^{-1}$ were also observed in the spectrum. In the FTIR spectrum of the prepared CN (Fig. 2d), the SCE peaks at 1602 and $1662 \mathrm{~cm}^{-1}$ were found to have disappeared, with an emergence of a peak at $1635 \mathrm{~cm}^{-1}$ indicating a possibility of conjugation of the two compounds, leading to the formation of a naturosome. The disappearance of peak at $1563 \mathrm{~cm}^{-1}$ (exhibiting the aromatic ring stretching) may be due to the weakening, or removal, or shielding by the phospholipid molecule, which may further support the formation of naturosome. This phenomenon may be explained as occurring due to the entrapment/packing of the SCE in the hydrophobic cavity of the formed phospholipid vesicle, and being held by van der Waals forces, and other hydrophobic interactions (44). The presence of the peaks at 1468, 1418, and $1378 \mathrm{~cm}^{-1}$ exhibits the $\mathrm{C}-\mathrm{H}$ bending and rocking. These peaks were found in both Phospholipon ${ }^{\circledR} 90 \mathrm{H}$, as well as in the physical mixture; and remained consistent in the complex with a negligible shift from original scale, indicating their lack of involvement in the formation of the naturosome.

\section{Differential Scanning Calorimetry}

The interactions between multiple components of a formulation is commonly analyzed by differential scanning calorimetry (DSC). Such interactions are typically observed as the elimination of endothermic peaks, appearance of new peaks, changes in peak shape and its onset, peak temperature/melting point and relative peak area, or enthalpy (45). Figure 3 shows the DSC thermograms of (a) pure SCE, (b) Phospholipon ${ }^{\circledR} 90 \mathrm{H}$, (c) $\mathrm{PM}$, and (d) CN. The pure SCE (a) revealed a broad endothermic peak around $94.4^{\circ} \mathrm{C}$. Phospholipon ${ }^{\circledR} 90 \mathrm{H}$ showed two sharp endothermic peaks at $125.2^{\circ} \mathrm{C}$ and $182.5^{\circ} \mathrm{C}$, respectively (b). The first peak (at $125.2^{\circ} \mathrm{C}$ ) is likely due to the melting of phospholipid. The second peak (at $182.5^{\circ} \mathrm{C}$ ) appears to be due to the phase-transition from gel to a liquid-crystalline state, and the carbon-chain in the phospholipid may have perhaps undergone other isomeric or crystal changes (46). In the physical mixture (PM) of the SCE and Phospholipon ${ }^{\circledR} 90 \mathrm{H}$ (Fig. 3c), the two peaks are observed at $100.9^{\circ} \mathrm{C}$ and at $123.6^{\circ} \mathrm{C}$. It may be assumed that with the rise in temperature, the Phospholipon ${ }^{\circledR} 90 \mathrm{H}$ melts, and the SCE gets dissolved in it, partly forming the naturosome. The thermogram of the $\mathrm{CN}$ exhibits two partially fused, broad endothermic peaks at $68.8^{\circ} \mathrm{C}$ and $85.9^{\circ} \mathrm{C}$, respectively (Fig. $3 \mathrm{~d}$ ). These peaks differed from the peak of SCE and Phospholipon ${ }^{\circledR} 90 \mathrm{H}$. A reduction in the melting point and enthalpy may account for the increased solubility, and reduced crystallinity of the drugs (47). It was thus evident that the original peaks of SCE and Phospholipon ${ }^{\circledR}$ $90 \mathrm{H}$ disappeared from the thermogram of the $\mathrm{CN}$, and the phase transition temperature was lower than that of Phospholipon ${ }^{\circledR}$ $90 \mathrm{H}$, thus confirming the formation of the drug-phospholipid complex. These findings are in agreement with those reported in the literature, and the interaction between the SCE and Phospholipon ${ }^{\circledR} 90 \mathrm{H}$ can be attributed to a combination of forces such as hydrogen bonding and van der Waals interactions, and can be considered as an indication of drug amorphization and/or complex formation, as supported by IR spectroscopy $(48,49)$. The interaction of the SCE with the polar region of Phospholipon ${ }^{\circledR} 90 \mathrm{H}$ may have been followed by the entrapment of SCE with the long-chain hydrocarbon tail of 


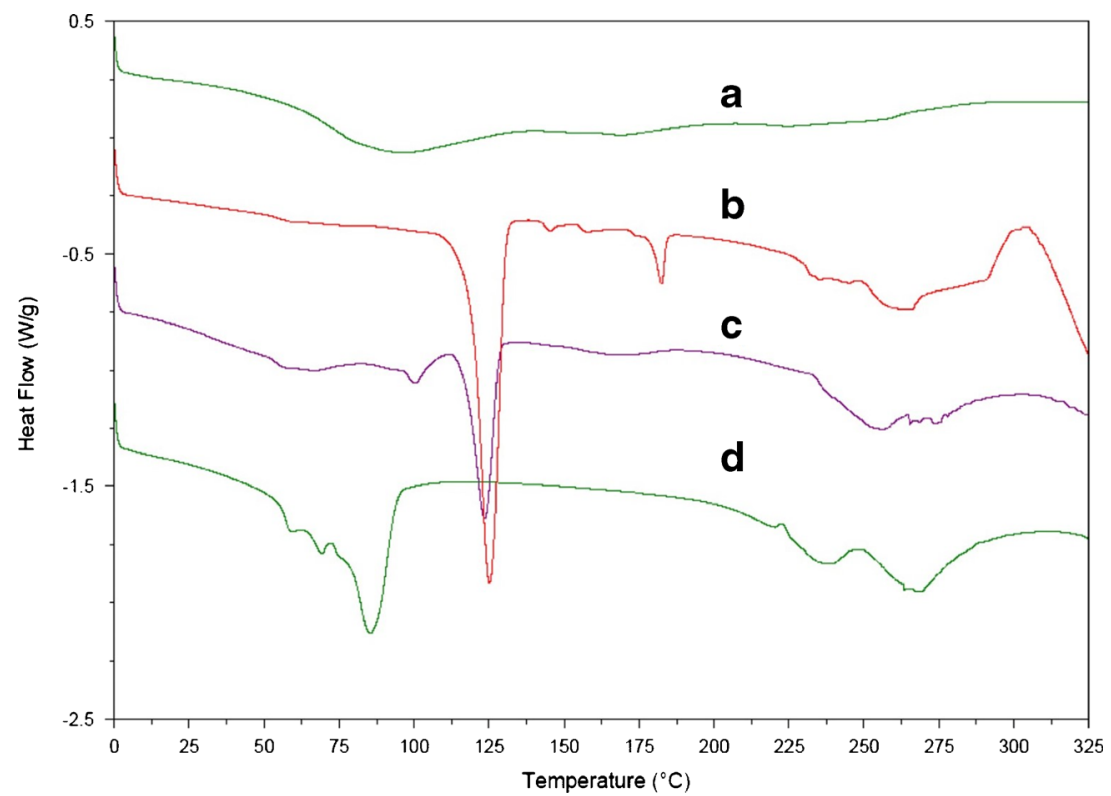

Fig. 3. DSC thermograms of $a \mathrm{SCE}, b$ Phospholipon ${ }^{\circledR} 90 \mathrm{H}, c$ physical mixture, and $d \mathrm{CN}$

phospholipid molecules. This resulted in the sequential decrease in phospholipid hydrocarbon chains and the disappearance of the second endothermic peak of Phospholipon ${ }^{\circledR} 90 \mathrm{H}$ with a reduction in the phase transition temperature (45).

\section{Powder X-Ray Diffraction}

Figure 4 displays the powder $\mathrm{x}$-ray diffraction (PXRD) patterns of (a) SCE, (b) Phospholipon $® 90 \mathrm{H}$, (c) PM, and (d) CN. The diffractogram of the SCE (Fig. 4a) revealed sharp
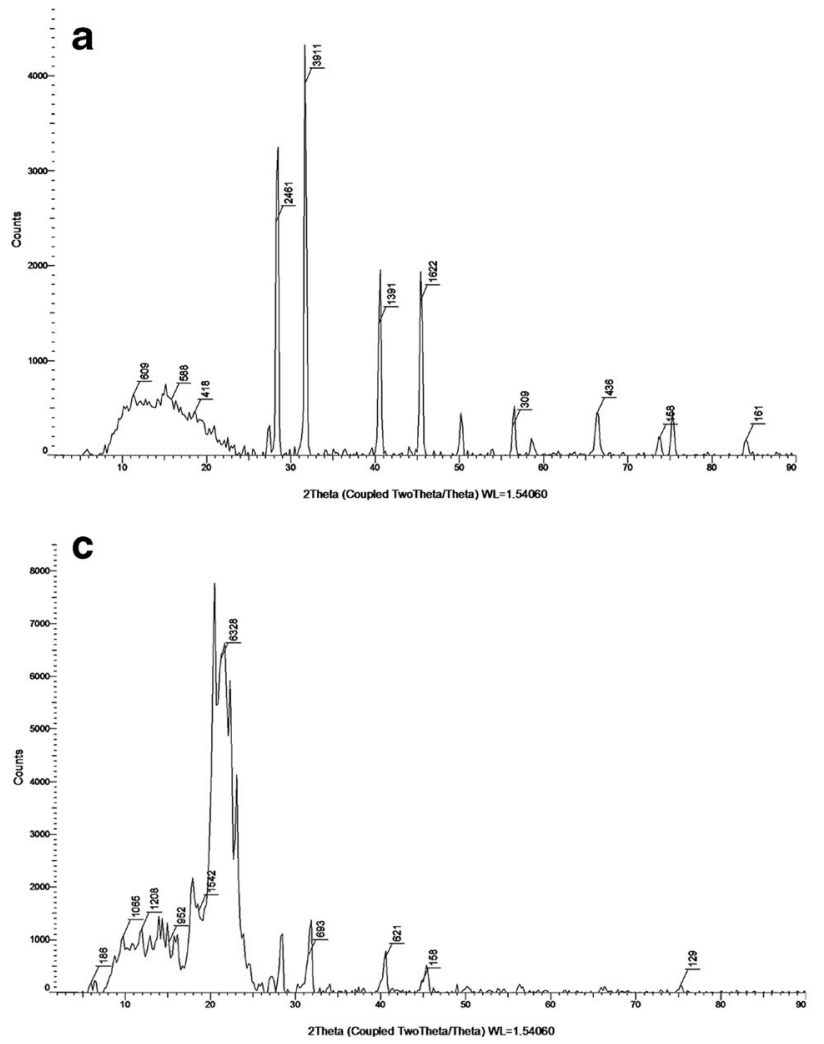

crystalline peaks at $2 \theta=46.0^{\circ}, 41.0^{\circ}, 32.0^{\circ}$, and $28.0^{\circ}$. A single diffraction peak was observed at $2 \theta=21.0^{\circ}$ for Phospholipon $\AA$ $90 \mathrm{H}$ (Fig. 4b). The physical mixture (PM) showed most of the peaks associated with the SCE and Phospholipon ${ }^{\circledR} 90 \mathrm{H}$ (Fig. 4c). In comparison to the physical mixture, the diffractogram of the $\mathrm{CN}$ revealed the disappearance of most of the crystalline peaks associated with the SCE (Fig. 4d). These results were in agreement with the previously reported studies, where the disappearance of the active pharmaceutical ingredient (API) peaks was associated with the formation of API-
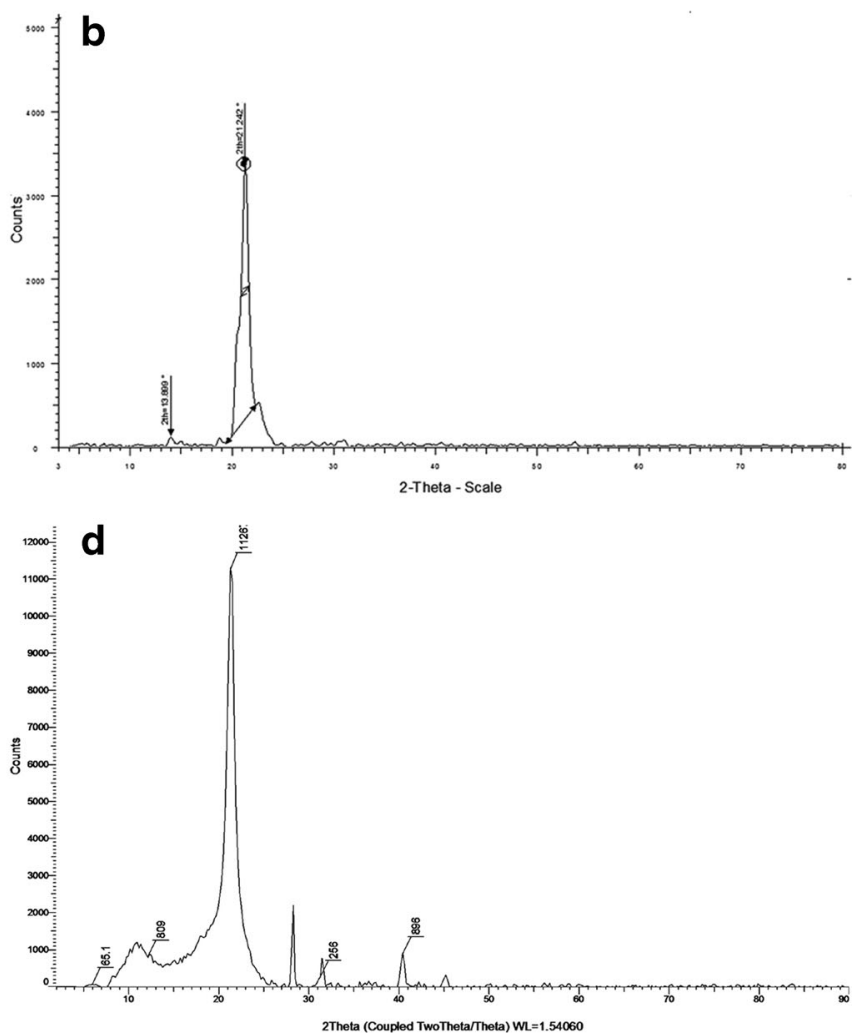

Fig. 4. PXRD spectra of a SCE, b Phospholipon ${ }^{\circledR} 90 \mathrm{H}$, c physical mixture, and d CN 
phospholipid complexes $(44,48)$. The disappearance of the SCE crystalline peaks thus confirmed the formation of SCEphospholipid complex. It may then also be concluded that the SCE in the Phospholipon ${ }^{\circledR} 90 \mathrm{H}$ matrix may be present either as a molecularly dispersed or an amorphous state (50).

\section{Functional Evaluation of CN}

\section{Apparent Solubility}

The results of the measured apparent solubilities of the pure SCE, the physical mixture of SCE, and Phospholipon ${ }^{\circledR}$ $90 \mathrm{H}(\mathrm{PM})$, and the prepared SCE-Phospholipon ${ }^{\circledR} 90 \mathrm{H}$ complex (CN) are shown in Table III. It was observed that the pure SCE had poor aqueous solubility $(\sim 8 \mu \mathrm{g} / \mathrm{mL})$, and a relatively higher solubility in $\mathrm{n}$-Octanol $(\sim 325 \mu \mathrm{g} / \mathrm{mL})$, indicating a rather lipophilic nature of the drug. The physical mixture (PM) revealed a non-significant change in the n-Octanol solubility, and a modest increase ( 1.5 times) in the aqueous solubility. The prepared SCE-Phospholipon ${ }^{\circledR} 90 \mathrm{H}$ complex (CN), however, showed a dramatic, and a significant (over 12-fold) increase in the aqueous solubility. This increase in the solubility of the prepared complex may be explained by the partial amorphization (reduced molecular crystallinity) of the drug, and the overall amphiphilic nature of the naturosome $(32,51)$.

\section{In Vitro Drug Release (Dissolution)}

The results of in vitro drug release studies are shown in the Fig. 5. The 12-h dissolution in the phosphate buffer $(\mathrm{pH}$ 6.8) revealed that, the pure SCE showed the slowest rate of dissolution, i.e., at the end of the dissolution period only about $39 \% w / w$ of SCE was dissolved. The dissolution rate of the physical mixture was found not to be significantly different $(\sim 42 \% w / w$ dissolved in $12 \mathrm{~h})$ compared to the pure SCE. The prepared $\mathrm{CN}$, however, revealed a significantly faster release of SCE at the end of dissolution period. The dissolution profile of the $\mathrm{CN}$ followed a near zero-order release, and at the end of $12 \mathrm{~h}$, over $99 \% w / w$ SCE was observed to be released from the $\mathrm{CN}$. The dissolution rate is largely influenced by the crystal morphology and the wettability of the solids, and the improved dissolution rate of SCE from the $\mathrm{CN}$ may be explained by the improved solubility, and the partially disrupted crystalline phase (amorphous form) in the prepared naturosome $(5,50)$. The relatively higher amorphous state of the naturosome, and their increased water-solubility may have had a positive impact on the cumulative release of the drug.

Table III. Solubility Study of SCE, PM, and CN

\begin{tabular}{lll}
\hline Sample & Aqueous solubility $(\mu \mathrm{g} / \mathrm{mL}) *$ & $\mathrm{n}$-Octanol solubility $(\mu \mathrm{g} / \mathrm{mL}) *$ \\
\hline SCE & $8.12 \pm 0.44$ & $325 \pm 7$ \\
PM & $13.6 \pm 0.4$ & $331 \pm 6$ \\
CN & $98.0 \pm 1.4$ & $343 \pm 7$ \\
\hline
\end{tabular}

*Data expressed as mean \pm Std. Dev.; $n=3$

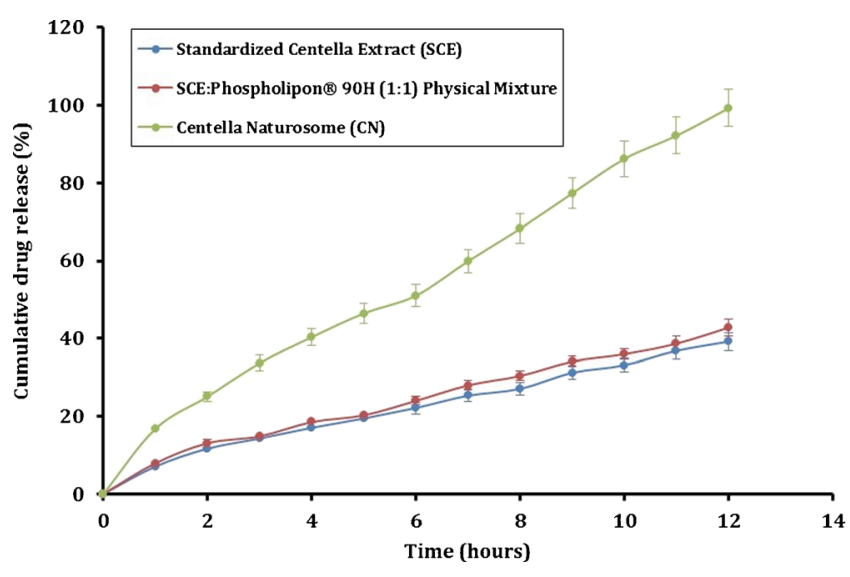

Fig. 5. In vitro dissolution study of SCE, PM, and CN

$D E$

The dissolution efficiencies of the pure SCE, the physical mixture of SCE and Phospholipon ${ }^{\circledR} 90 \mathrm{H}$ (PM), and the prepared SCE-Phospholipon ${ }^{\circledR} 90 \mathrm{H}$ complex $(\mathrm{CN})$ calculated from the in vitro release studies in phosphate buffer $(\mathrm{pH} 6.8)$ were calculated using Eq. 4 (Suppl. Table 3). The prepared $\mathrm{CN}$ showed a significantly $(p<0.001)$ improved dissolution efficiency compared to the pure SCE. Almost 2.4-fold increase in the DE was observed for $\mathrm{CN}$ in PBS at the end of $12 \mathrm{~h}$, compared to the pure SCE. This significant increase can be attributed to the enhancement of SCE solubility in the prepared naturosome. A marginal, but a statistically significant $(p<0.01)$ increase in dissolution efficiency of SCE in physical mixture compared to the pure SCE was also observed. The solubilizing ability of the phospholipids, owing to their amphiphilic nature is likely the reason for this observed increase in the release of SCE.

\section{Ex Vivo Permeability}

The results of the ex vivo permeability study as carried out with the everted intestine method on the pure SCE, the physical mixture of SCE and Phospholipon ${ }^{\circledR} 90 \mathrm{H}(\mathrm{PM})$, and the prepared SCE-Phospholipon $\AA 90 \mathrm{H}$ complex $(\mathrm{CN})$ are shown in Fig. 6. The permeability of the tested samples appeared to follow the trends observed in the in vitro release

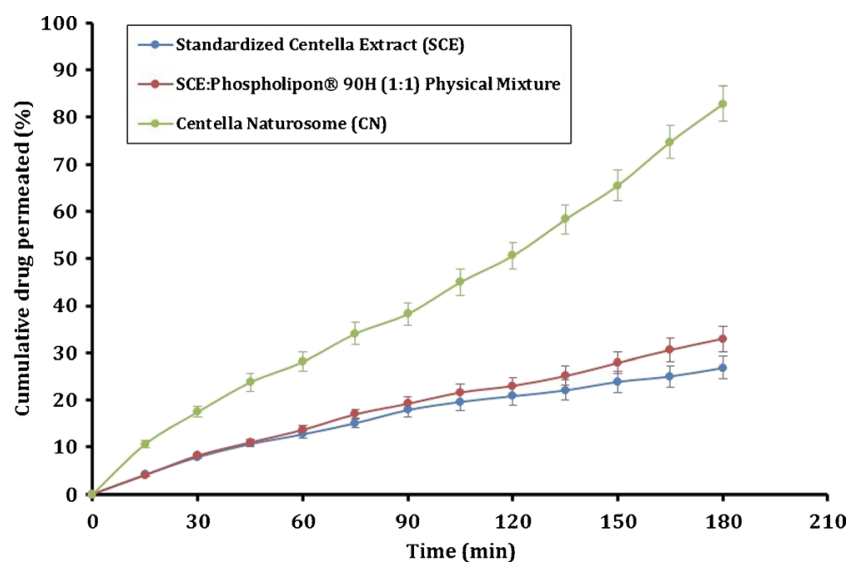

Fig. 6. Ex vivo permeability study of SCE, PM, and CN 
study. It was observed that, at the end of 3-h study duration, only about $26 \% w / w$ of the pure SCE permeated through the everted intestine. The physical mixture (PM) showed a marginal, but a non-significant improvement in the permeation of SCE. The prepared $\mathrm{CN}$, however, demonstrated a significantly improved permeation of SCE across the everted intestine. At the end of 3-h testing period, over $80 \% \mathrm{w} / \mathrm{w}$ of SCE was found to permeate across the biological membrane. The phospholipids being amphiphilic in nature, may behave as surfactants and contribute towards the increased permeability of the drug across the membrane. Due to the observed improved solubility, increased dissolution rate, and observed increased permeability of the SCE in the prepared $\mathrm{CN}$, this approach of the drug-phospholipid complexation lends itself to be a promising formulation strategy for the enhanced delivery of SCE to the physiology.

\section{Preliminary Pharmacological Evaluation (In Vivo Efficacy)}

The results of the preliminary pharmacological evaluation (in vivo efficacy) of the prepared SCE-phospholipid complex $(\mathrm{CN})$ are shown in Fig. 7. A group of young mice $(n=6)$ was treated with the vehicle (saline). The aged mice ( $n=6 /$ group) were administered with vehicle (saline), Phospholipon ${ }^{\circledR} 90 \mathrm{H}(900 \mathrm{mg} / \mathrm{kg})$, piracetam $(200 \mathrm{mg} / \mathrm{kg})$, $\mathrm{SCE}(300 \mathrm{mg} / \mathrm{kg}), \mathrm{PM}(300 \mathrm{mg} / \mathrm{kg})$ or $\mathrm{CN}(300 \mathrm{mg} / \mathrm{kg} \mathrm{SCE}$ equivalent) via oral route as shown in Fig. 7a. It was observed that the escape latency, i.e., the time taken by the animal to

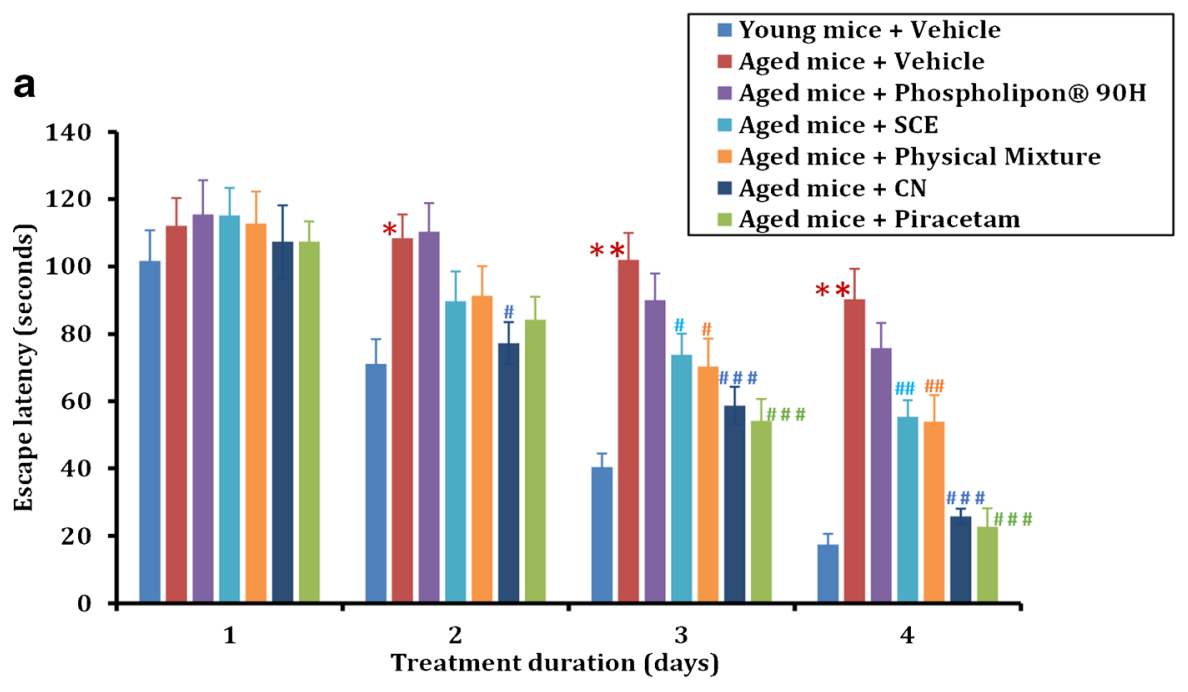

b

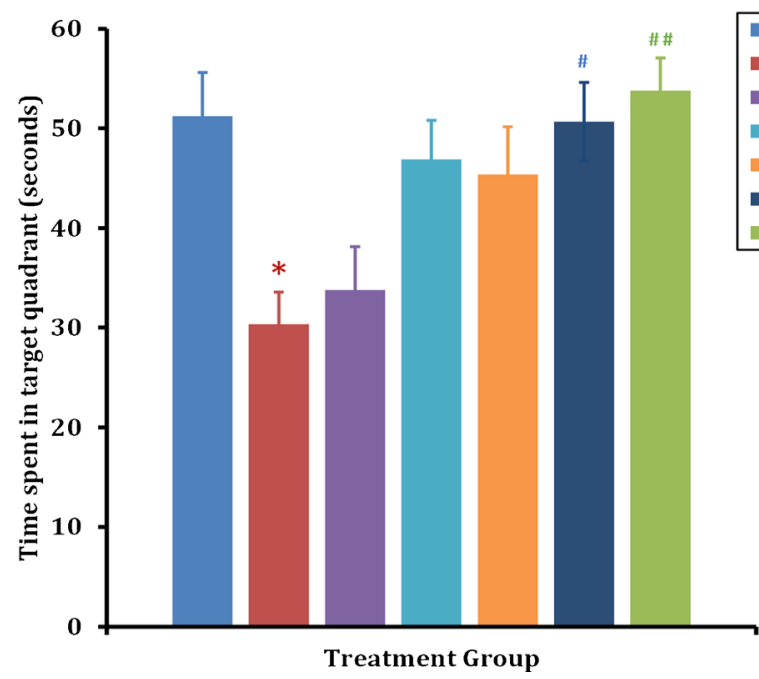

Young mice + Vehicle

aged mice + Vehicle

aged mice + Phospholipon $\left({ }^{\circledR} 90 \mathrm{H}\right.$

Aged mice + SCE

Aged mice + Physical Mixture

aged mice $+\mathrm{CN}$

Aged mice + Piracetam

Fig. 7. Effect of standardized Centella extract (SCE) and Centella naturosomes (CN) on spatial learning and memory in the Morris Water Maze (MWM) test. a Young and aged animals were treated with vehicle (saline), Phospholipon ${ }^{\circledR} 90 \mathrm{H}(900 \mathrm{mg} / \mathrm{kg})$, piracetam $(200 \mathrm{mg} / \mathrm{kg})$, SCE $(300 \mathrm{mg} / \mathrm{kg}$ ), physical mixture (equivalent to $300 \mathrm{mg} / \mathrm{kg} \mathrm{SCE}$ ), or $\mathrm{CN}$ (equivalent to $300 \mathrm{mg} / \mathrm{kg}$ $\mathrm{SCE}$ ) via oral route, and $1 \mathrm{~h}$ later subjected to assessment of escape latency in a 4-day acquisition trial in MWM test. Data are expressed as mean \pm SEM. $* p<0.01, * * p<0.001 v s$ young mice + vehicle; ${ }^{\#} p<0.05,{ }^{\#} p<0.01, \# \#{ }^{\#} p<0.001$ vs aged mice + vehicle. b Total time spent by the animals in the target quadrant during the probe trial on day 5. Data are expressed as mean \pm SEM. $* p<0.05 v s$ young mice + vehicle; ${ }^{\#} p<0.05,{ }^{\#}{ }^{\#} p<0.01$ vs aged mice + vehicle 
locate the platform, in the young mice treated with vehicle progressively and significantly decreased during the 4-day training period (Fig. 7a). This indicated a quicker learning and adaptation to the surroundings by these animals. The aged animals treated with the vehicle, however, exhibited a significantly higher escape latency $(p<0.01$ on day $2, p<0.001$ on days 3 and 4), that did not appear to significantly improve at the end of the 4-day training period. The aged animals treated with piracetam, SCE, or $\mathrm{CN}$ showed a significant decrease in the escape latency at the end of the 4-day training period. The application of two-way ANOVA showed the main effect of treatments $[F(4,100)=26.02 ; p<0.0001]$, acquisition days $[F(3,100)=81.45 ; p<0.0001]$, and their interaction $[F(12,100)=2.906 ; p<0.01]$. The post hoc Bonferroni multiple comparison test also revealed that all the treatments (piracetam, $p<0.001$ on days 3 and 4; SCE, $p<0.05$ on day 3 , and $p<0.01$ on day 4 or $\mathrm{CN}, p<0.05$ on day 2 and $p<0.001$ on days 3 and 4 ) in aged animals significantly reduced escape latency on day 2 onward as compared to the vehicle-treated aged animal group. While the $\mathrm{CN}$ and piracetam showed similar effects on the escape latency ( $p>0.05), \mathrm{CN}$ exhibited higher efficacy in terms of reduction in the escape latency as compared to the pure SCE $(p<0.05)$. However, a 4-day alone treatment with Phospholipon ${ }^{\circledR} 90 \mathrm{H}$ in aged mice did not reveal any significant improvements in the escape latency compared to the vehicle-treated mice.

In addition, the application of one-way ANOVA showed a significant effect of piracetam, SCE, or CN treatments on time spent in the target quadrant $[F(4,29)=6.221 ; p<0.01]$ at the end of 5 days (Fig. 7b). The Bonferroni multiple comparison test revealed that aged animals treated with vehicle did not recognize the target quadrant, and therefore spent less time in that quadrant compared to the vehicletreated young animals $(p<0.05)$. However, oral treatments of piracetam $(p<0.01)$, or $\mathrm{CN}(p<0.05)$ significantly increased the time spent in the target quadrant compared to the vehicle-treated aged animals, thus confirming the potential effect of Centella extract on memory as reported in earlier studies $(37,38)$. Centella extract is known to improve the morphology and arborization of hippocampal neuronal dendrites (52,53). Moreover, its negative effect on reactive oxygen species and superoxide formation along with decrease in glutathione and activation of glutathione-Stransferase, have reportedly the key mechanisms involved in its nootropic action (37).

It was interesting to note here that $\mathrm{CN}$ treatment showed a comparable effect to that of the standard piracetam treatment $(p>0.05)$, i.e., the $\mathrm{CN}$-treated animals spent more time in the target quadrant. The SCE-treated mice, which show an increased time spent in the target quadrant compared to the vehicle group, was not statistically significant. Thus, we suggest that although both SCE or CN administration improves the spatial learning and memory in aged mice, $\mathrm{CN}$ exhibits better efficacy compared to SCE in MWM. The improvement in the relative absorption of $\mathrm{CN}$ after oral administration might be attributed to the following factors: SCE being lipophilic in nature, its absorption and bioavailability is dissolution rate limited. Interactions between the non-polar, fatty acid component of phospholipid and the SCE could have enhanced the overall hydrophilicity and solubility of $\mathrm{CN}$ (3). This may have possibly resulted in an improved dissolution efficiency of the $\mathrm{CN}$. In addition, the smaller particle size of the prepared $\mathrm{CN}$ might have led to enhanced relative absorption of SCE after oral administration. The extended release of SCE from $\mathrm{CN}$, along with a decreased metabolism, may also confer a prolonged duration of action and higher bioavailability (28). Furthermore, as reported in the previous studies, the intestinal transport and the absorption mechanisms might also be the possible contributors to the improved $\mathrm{CN}$ oral bioavailability $(54,55)$.

Several studies have previously reported the influence of phospholipids on memory improvement (56-59). Since a phospholipid was employed in the present study as a carrier for the SCE in the formulation of the $\mathrm{CN}$, we examined the possibility of the memory-enhancement effects of Phospholipon ${ }^{\circledR} 90 \mathrm{H}$. The results from Phospholipon ${ }^{\circledR} 90 \mathrm{H}-$ treated aged mice group showed no significant improvement in the escape latency or the time spent in the target quadrant after a 4-day treatment period. Nagata et al. and Yaguchi et al. in their studies noted that oral administration of 1,2dilynoleoylsnglycero-3-phosphocholine (DLPhtCho) alone or in combination with 1-palmitoyl-2-oleoylsnglycero-3phosphocholine (POPhtCho) predominantly blocked the scopolamine-induced dementia, but these effects were less pronounced in normal animals $(57,58)$. Additionally, unlike the 4-day treatment protocol employed in the present study, previous studies evaluating phospholipids followed longer durations of drug treatment, which may have contributed to the improved learning and memory observed with phospholipids $(57,59,60)$. The dose and the duration of therapy appears to be important parameters in the pro-cognitive effects observed with phospholipids. Thus, in the present study, the improved learning and memory following $\mathrm{CN}$ treatment can be attributed purely to the intrinsic action of Centella extract, and the contribution of Phospholipon ${ }^{\circledR} 90 \mathrm{H}$ appears to be non-significant.

\section{CONCLUSIONS}

In the present study, an attempt was made to enhance the aqueous solubility of SCE via its complexation with phospholipids (preparation of naturosomes). A central composite design was used to optimize the formulation and process variables. The prepared $\mathrm{CN}$ were evaluated for physicochemical, functional, and pharmacological attributes. The FTIR, DSC, PXRD, photomicroscopy, and the SEM studies indicated the successful formation of vesicular drugphospholipid complex. The apparent solubility, the in vitro dissolution, and the ex vivo permeability studies indicated a significant improvement in the aqueous solubility, the drug release, and the membrane permeation of the SCE from the $\mathrm{CN}$, respectively. The preliminary in vivo pharmacological evaluation revealed a significantly higher efficacy (likely due to improved bioavailability) of the prepared $\mathrm{CN}$ compared to the pure extract and a comparable efficacy with the standard drug, piracetam $(200 \mathrm{mg} / \mathrm{kg})$. The exact mechanism of the improved efficacy of the prepared $\mathrm{CN}$, as well as the contribution of individual triterpenes to the pharmacological activity will require further detailed investigation. Additional studies analyzing the pharmacokinetic parameters are required to substantiate the increased absorption, and the enhanced bioavailability hypothesis. 


\section{REFERENCES}

1. [WHO guidelines for governments and consumers regarding the use of alternative therapies]. Rev Panam Salud Publica. 2004;16(3):218-21.

2. Teng Z, Yuan C, Zhang F, Huan M, Cao W, Li K, et al. Intestinal absorption and first-pass metabolism of polyphenol compounds in rat and their transport dynamics in Caco-2 cells. PLoS One. 2012;7(1):e29647. doi:10.1371/journal.pone.0029647.

3. Khan J, Alexander A, Ajazuddin, Saraf S. Recent advances and future prospects of phyto-phospholipid complexation technique for improving pharmacokinetic profile of plant actives. J Control Release. 2013;168(1):50-60. doi:10.1016/j.jconrel.2013.02.025.

4. Husch J, Bohnet J, Fricker G, Skarke C, Artaria C, Appendino $\mathrm{G}$, et al. Enhanced absorption of boswellic acids by a lecithin delivery form (phytosome $((\mathrm{R}))$ ) of Boswellia extract. Fitoterapia. 2013;84:89-98. doi:10.1016/j.fitote.2012.10.002.

5. Freag MS, Elnaggar YS, Abdallah OY. Lyophilized phytosomal nanocarriers as platforms for enhanced diosmin delivery: optimization and ex vivo permeation. Int $\mathrm{J}$ Nanomedicine. 2013;8:2385-97. doi:10.2147/ijn.s45231.

6. Kennedy DO, Haskell CF, Mauri PL, Scholey AB. Acute cognitive effects of standardised Ginkgo biloba extract complexed with phosphatidylserine. Hum Psychopharmacol. 2007;22(4):199-210. doi:10.1002/hup.837.

7. Mukherjee K, Venkatesh M, Venkatesh P, Saha BP, Mukherjee PK. Effect of soy phosphatidyl choline on the bioavailability and nutritional health benefits of resveratrol. Food Res Int. 2011:44(4):1088-93. doi:10.1016/j.foodres.2011.03.034.

8. Pathan R, Bhandari U. Preparation \& characterization of embelin-phospholipid complex as effective drug delivery tool. J Incl Phenom Macrocycl Chem. 2011;69(1-2):139-47. doi:10.1007/ s10847-010-9824-2.

9. Zaidi SMA, Pathan SA, Ahmad FJ, Surender S, Jamil S, Khar RK. Neuropharmacological evaluation of paeonia emodi root extract phospholipid complex in mice. Planta Med. 2011;77(05):P_123. doi:10.1055/s-0031-1273652.

10. Huang Y, Mucke L. Alzheimer mechanisms and therapeutic strategies. Cell. 2012;148(6):1204-22. doi:10.1016/ j.cell.2012.02.040.

11. Association as Alzheimer's disease facts and figures. Alzeimer's \& Dimentia. 2014;10(2).

12. Cappell J, Herrmann N, Cornish S, Lanctot KL. The pharmacoeconomics of cognitive enhancers in moderate to severe Alzheimer's disease. CNS Drugs. 2010;24(11):909-27. doi:10.2165/11539530-000000000-00000.

13. Paris D, Mathura V, Ait-Ghezala G, Beaulieu-Abdelahad D, Patel N, Bachmeier C, et al. Flavonoids lower Alzheimer's Abeta production via an NFkappaB dependent mechanism. Bioinformation. 2011;6(6):229-36.

14. Jones WP, Chin YW, Kinghorn AD. The role of pharmacognosy in modern medicine and pharmacy. Curr Drug Targets. 2006;7(3):247-64.

15. Akhondzadeh S, Noroozian M, Mohammadi M, Ohadinia S, Jamshidi AH, Khani M. Salvia officinalis extract in the treatment of patients with mild to moderate Alzheimer's disease: a double blind, randomized and placebo-controlled trial. J Clin Pharm Ther. 2003;28(1):53-9.

16. Ha GT, Wong RK, Zhang Y. Huperzine a as potential treatment of Alzheimer's disease: an assessment on chemistry, pharmacology, and clinical studies. Chem Biodivers. 2011;8(7):1189-204. doi:10.1002/cbdv.201000269.

17. Hossain S, Hashimoto M, Katakura M, Al Mamun A, Shido O. Medicinal value of asiaticoside for Alzheimer's disease as assessed using single-molecule-detection fluorescence correlation spectroscopy, laser-scanning microscopy, transmission electron microscopy, and in silico docking. BMC Compl Altern Med. 2015;15:118. doi:10.1186/s12906-015-0620-9.

18. Lee TF, Shiao YJ, Chen CF, Wang LC. Effect of ginseng saponins on beta-amyloid-suppressed acetylcholine release from rat hippocampal slices. Planta Med. 2001;67(7):634-7. doi:10.1055/s-2001-17366.

19. Zhang L, Qin C, Yuan S, Wang S. Application of Evodiamine in preparing medicaments for Alzheimer's disease. In: USPTO, editor. Google Patents. USA: Institute Of Laboratory Animal Science, Chinese Academy Of Medical Sciences; 2011.

20. Brinkhaus B, Lindner M, Schuppan D, Hahn EG. Chemical, pharmacological and clinical profile of the East Asian medical plant Centella asiatica. Phytomedicine. 2000;7(5):427-48.

21. Hashim P, Sidek H, Helan MH, Sabery A, Palanisamy UD, Ilham M. Triterpene composition and bioactivities of Centella asiatica. Molecules. 2011;16(2):1310-22. doi:10.3390/ molecules16021310.

22. Upadhyay SK, Saha A, Bhatia BD, Kulkarni KS. Evaluation of the efficacy of Mentat in children with learning disability: a placebo-controlled double-blind clinical trial. Neurosci Today. 2002;VI(3):184-8.

23. Dave VS, Saoji SD, Raut NA, Haware RV. Excipient variability and its impact on dosage form functionality. J Pharm Sci. 2015;104(3):906-15. doi:10.1002/jps.24299.

24. Bhattacharyya S, Majhi S, Saha BP, Mukherjee PK. Chlorogenic acid-phospholipid complex improve protection against UVA induced oxidative stress. J Photochem Photobiol B. 2014:130:293-8. doi:10.1016/j.jphotobiol.2013.11.020.

25. Yue PF, Zhang WJ, Yuan HL, Yang M, Zhu WF, Cai PL, et al. Process optimization, characterization and pharmacokinetic evaluation in rats of ursodeoxycholic acid-phospholipid complex. AAPS PharmSciTech. 2008;9(1):322-9. doi:10.1208/s12249-008-9040-1.

26. Yue P-F, Yuan H-L, Li X-Y, Yang M, Zhu W-F. Process optimization, characterization and evaluation in vivo of oxymatrine-phospholipid complex. Int J Pharm. 2010;387(12):139-46. doi:10.1016/j.ijpharm.2009.12.008.

27. Bhattacharyya S, Ahammed SM, Saha BP, Mukherjee PK. The gallic acid-phospholipid complex improved the antioxidant potential of gallic acid by enhancing its bioavailability. AAPS PharmSciTech. 2013;14(3):1025-33. doi:10.1208/s12249-013-9991-8.

28. Tan Q, Liu S, Chen X, Wu M, Wang H, Yin H, et al. Design and evaluation of a novel evodiamine-phospholipid complex for improved oral bioavailability. AAPS PharmSciTech. 2012;13(2):534-47. doi:10.1208/s12249-012-9772-9.

29. Bhattacharyya S, Ahmmed SM, Saha BP, Mukherjee PK. Soya phospholipid complex of mangiferin enhances its hepatoprotectivity by improving its bioavailability and pharmacokinetics. J Sci Food Agric. 2014;94(7):1380-8. doi:10.1002/ jsfa.6422.

30. Sze A, Erickson D, Ren L, Li D. Zeta-potential measurement using the Smoluchowski equation and the slope of the currenttime relationship in electroosmotic flow. J Colloid Interface Sci. 2003;261(2):402-10. doi:10.1016/s0021-9797(03)00142-5.

31. Saoji SD, Atram SC, Dhore PW, Deole PS, Raut NA, Dave VS. Influence of the component excipients on the quality and functionality of a transdermal film formulation. AAPS PharmSciTech. 2015. doi:10.1208/s12249-015-0322-0.

32. Singh D, Rawat MSM, Semalty A, Semalty M. Chrysophanolphospholipid complex. J Therm Anal Calorim. 2013;111(3):206977. doi:10.1007/s10973-012-2448-6.

33. Zhang Z, Chen Y, Deng J, Jia X, Zhou J, Lv H. Solid dispersion of berberine-phospholipid complex/TPGS 1000/SiO2: preparation, characterization and in vivo studies. Int $\mathrm{J}$ Pharm. 2014;465(1-2):306-16. doi:10.1016/j.ijpharm.2014.01.023.

34. Anderson NH, Bauer M, Boussac N, Khan-Malek R, Munden P, Sardaro M. An evaluation of fit factors and dissolution efficiency for the comparison of in vitro dissolution profiles. J Pharm Biomed Anal. 1998;17(4-5):811-22.

35. Dixit P, Jain DK, Dumbwani J. Standardization of an ex vivo method for determination of intestinal permeability of drugs using everted rat intestine apparatus. J Pharmacol Toxicol Methods. 2012;65(1):13-7. doi:10.1016/j.vascn.2011. 11.001 .

36. Vorhees CV, Williams MT. Morris water maze: procedures for assessing spatial and related forms of learning and memory. Nat Protoc. 2006;1(2):848-58. doi:10.1038/nprot.2006.116.

37. Kumar A, Dogra S, Prakash A. Neuroprotective effects of Centella asiatica against intracerebroventricular colchicineinduced cognitive impairment and oxidative stress. Int J Alzheimers Dis. 2009. doi:10.4061/2009/972178.

38. Veerendra Kumar MH, Gupta YK. Effect of different extracts of Centella asiatica on cognition and markers of oxidative stress in rats. J Ethnopharmacol. 2002;79(2):253-60. 
39. Qin X, Yang Y, Fan TT, Gong T, Zhang XN, Huang Y. Preparation, characterization and in vivo evaluation of bergenin-phospholipid complex. Acta Pharmacol Sin. 2010;31(1):127-36. doi:10.1038/aps.2009.171.

40. LeFevre ME, Olivo R, Vanderhoff JW, Joel DD. Accumulation of latex in Peyer's patches and its subsequent appearance in villi and mesenteric lymph nodes. Proc Soc Exp Biol Med. 1978;159(2):298-302.

41. Savic R, Luo L, Eisenberg A, Maysinger D. Micellar nanocontainers distribute to defined cytoplasmic organelles. Science. 2003;300(5619):615-8. doi:10.1126/science.1078192.

42. Freitas C, Müller RH. Effect of light and temperature on zeta potential and physical stability in solid lipid nanoparticle (SLNTM) dispersions. Int J Pharm. 1998;168(2):221-9. doi:10.1016/S0378-5173(98)00092-1.

43. Rarokar NR, Saoji SD, Raut NA, Taksande JB, Khedekar PB, Dave VS. Nanostructured cubosomes in a thermoresponsive depot system: an alternative approach for the controlled delivery of docetaxel. AAPS PharmSciTech. 2015. doi:10.1208/s12249-015-0369-y.

44. Jena SK, Singh C, Dora CP, Suresh S. Development of tamoxifen-phospholipid complex: novel approach for improving solubility and bioavailability. Int J Pharm. 2014;473(1-2):1-9. doi:10.1016/j.ijpharm.2014.06.056.

45. Maiti K, Mukherjee K, Gantait A, Saha BP, Mukherjee PK Curcumin-phospholipid complex: preparation, therapeutic evaluation and pharmacokinetic study in rats. Int $\mathrm{J}$ Pharm. 2007;330(1-2):155-63. doi:10.1016/j.ijpharm.2006.09.025.

46. Semalty A, Semalty M, Singh D, Rawat MSM. Phytophospholipid complex of catechin in value added herbal drug delivery. J Incl Phenom Macrocycl Chem. 2012;73(1-4):377-86. doi:10.1007/s10847-011-0074-8.

47. Singh D, Rawat MSM, Semalty A, Semalty M. Emodinphospholipid complex. J Therm Anal Calorim. 2012;108(1):289-98. doi:10.1007/s10973-011-1759-3.

48. Singh C, Bhatt TD, Gill MS, Suresh S. Novel rifampicinphospholipid complex for tubercular therapy: synthesis, physicochemical characterization and in-vivo evaluation. Int J Pharm. 2014:460(1-2):220-7. doi:10.1016/j.ijpharm.2013.10.043.

49. Zhang K, Gu L, Chen J, Zhang Y, Jiang Y, Zhao L, et al. Preparation and evaluation of kaempferol-phospholipid complex for pharmacokinetics and bioavailability in SD rats. J Pharm Biomed Anal. 2015;114:168-75. doi:10.1016/j.jpba.2015.05.017.

50. Semalty A, Semalty M, Singh D, Rawat MSM. Preparation and characterization of phospholipid complexes of naringenin for effective drug delivery. J Incl Phenom Macrocycl Chem. 2010;67(3-4):253-60. doi:10.1007/s10847-009-9705-8.

51. Xia HJ, Zhang ZH, Jin X, Hu Q, Chen XY, Jia XB. A novel drug-phospholipid complex enriched with micelles: preparation and evaluation in vitro and in vivo. Int $\mathrm{J}$ Nanomedicine. 2013;8:545-54. doi:10.2147/ijn.s39526.

52. Mohandas Rao KG, Muddanna Rao S, Gurumadhva RS. Centella asiatica (L.) leaf extract treatment during the growth spurt period enhances hippocampal CA3 neuronal dendritic arborization in rats. Evid Based Complement Alternat Medicine eCAM. 2006;3(3):349-57. doi:10.1093/ ecam/nel024.

53. Mohandas Rao KG, Muddanna Rao S, Gurumadhva RS. Enhancement of amygdaloid neuronal dendritic arborization by fresh leaf juice of Centella asiatica (Linn) during growth spurt period in rats. Evid Based Complement Alternat Med eCAM. 2009;6(2):203-10. doi:10.1093/ecam/nem079.

54. Sikarwar MS, Sharma S, Jain AK, Parial SD. Preparation, characterization and evaluation of marsupsin-phospholipid complex. AAPS PharmSciTech. 2008;9(1):129-37. doi:10.1208/ s12249-007-9020-x.

55. Yanyu X, Yunmei S, Zhipeng C, Qineng P. The preparation of silybin-phospholipid complex and the study on its pharmacokinetics in rats. Int J Pharm. 2006;307(1):77-82. doi:10.1016/ j.ijpharm.2005.10.001.

56. Ladd SL, Sommer SA, LaBerge S, Toscano W. Effect of phosphatidylcholine on explicit memory. Clin Neuropharmacol. 1993;16(6):540-9.

57. Nagata T, Yaguchi T, Nishizaki T. DL- and POphosphatidylcholines as a promising learning and memory enhancer. Lipids Health Dis. 2011;10:25. doi:10.1186/1476-511x10-25.

58. Yaguchi T, Nagata T, Nishizaki T. Dilinoleoylphosphatidylcholine ameliorates scopolamine-induced impairment of spatial learning and memory by targeting $\alpha 7$ nicotinic ACh receptors. Life Sci. 2009;84(9-10):263-6. doi:10.1016/j.lfs.2008.12.003.

59. Yaguchi T, Nagata T, Nishizaki T. 1-Palmitoyl-2-oleoyl-snglycero-3-phosphocholine improves cognitive decline by enhancing long-term depression. Behav Brain Res. 2009;204(1):129-32. doi:10.1016/j.bbr.2009.05.027.

60. Chung SY, Moriyama T, Uezu E, Uezu K, Hirata R, Yohena N, et al. Administration of phosphatidylcholine increases brain acetylcholine concentration and improves memory in mice with dementia. J Nutr. 1995;125(6):1484-9. 